\title{
Can unconfined ice shelves provide buttressing via hoop stresses?
}

\section{Paper}

Cite this article: Wearing MG, Kingslake J, Worster MG (2020). Can unconfined ice shelves provide buttressing via hoop stresses? Journal of Glaciology 66(257), 349-361. https://doi.org/ 10.1017/jog.2019.101

Received: 31 July 2019

Revised: 11 December 2019

Accepted: 12 December 2019

First published online: 13 February 2020

\section{Keywords:}

Antarctic glaciology; ice shelves; ice velocity; ice dynamics; ice-shelf break-up

Author for correspondence:

Martin G. Wearing,

E-mail: wearing@ldeo.columbia.edu (c) The Author(s) 2020. This is an Open Access article, distributed under the terms of the Creative Commons Attribution licence (http:// creativecommons.org/licenses/by/4.0/), which permits unrestricted re-use, distribution, and reproduction in any medium, provided the original work is properly cited.
Martin G. Wearing ${ }^{1} \mathbb{D}$, Jonathan Kingslake ${ }^{1}$ and M. Grae Worster ${ }^{2}$

${ }^{1}$ Lamont-Doherty Earth Observatory, Columbia University, New York, USA and ${ }^{2}$ Department of Applied Mathematics and Theoretical Physics, University of Cambridge, Cambridge, UK

\section{Abstract}

The stress balance within an ice shelf is key to the resistance, or buttressing, it can provide and in part controls the rate of ice discharge from the upstream ice sheet. Unconfined ice shelves are widely assumed to provide no buttressing. However, theory and laboratory-scale analogue experiments have shown that unconfined, floating viscous flows generate buttressing via hoop stresses. Hoop stress results from the viscous resistance to spreading perpendicular to the flow direction in a diverging flow. We build on theoretical work to explore the controls on the magnitude of hoopstress buttressing, deducing that buttressing increases with increasing effective viscosity and increasing divergence. We use an idealised model calibrated to unconfined sections of Antarctic ice shelves and find that many shelves have low effective viscosity, most likely due to extensive damage resulting from high extensional stresses. Therefore, they are unable to sustain the large hoop stresses required to resist flow. Some ice shelves that are surrounded by sea ice year-round have a greater effective viscosity and can provide buttressing, suggesting that sea ice reduces fracturing. However, we find that most unconfined ice shelves provide insignificant buttressing today, even when hoop stresses are considered in the stress balance.

\section{Introduction}

Ice shelves are the floating extensions of ice sheets and provide resistance to the flow of grounded ice upstream. This is known as ice-shelf buttressing. The magnitude of buttressing is determined by the viscous deformation of the ice shelf, which is dependent on: the geometry of the ice-shelf embayment; the location of pinning points within the shelf; the ice-shelf thickness (controlled by ice-shelf flow, surface and basal mass balance); ice-shelf extent (controlled by the position of the calving front and iceberg calving); ice rheology and structural integrity (controlled by ice temperature, damage and crevassing).

Ice-shelf thinning in key locations, such as near grounding lines (the boundary at which ice begins to float) and in shear margins, has been shown to decrease ice-shelf buttressing in numerical ice-flow models (Reese and others, 2018; Goldberg and others, 2018). Observations show that the collapse of ice shelves, and therefore the removal of buttressing, can lead to a rapid speed up and thinning of the grounded ice upstream (Rack and Rott, 2004; Rignot and others, 2004; Scambos and others, 2004).

Ice shelves are often found within embayments and are rarely observed to advance substantially outside of a lateral confinement. A small number of ice tongues (unconfined ice shelves) do exist and appear to be partially supported and prevented from collapsing by the presence of landfast sea ice for much of the year (see Fig. 1 and S7) (Cuffey and Paterson, 2010, p. 127).

The extent of present-day ice shelves providing significant buttressing has been determined by Fürst and others (2016). In this work, areas of ice shelves that provide little or no buttressing are classed as areas of passive ice that could be removed without triggering a significant increase in ice flow across the grounding line. These areas are consistently found close to the present-day calving front, often where the ice shelf begins to protrude out past the lateral confinement of pinning points. The buttressing number - a measure of resistance provided by the ice shelf - was used to inform the design of numerical ice-flow experiments to determine the extent of passive ice. Contours of maximum buttressing number were used to incrementally remove sections of the ice shelf in the model, while the instantaneous change in groundingline flux determined whether these regions were deemed passive (Fürst and others, 2016).

There is a long held assumption that unconfined ice shelves provide no buttressing and often ice-sheet models ignore the effects of unconfined ice shelves (Cuffey and Paterson, 2010 , p. 385). One mechanism by which unconfined ice shelves can theoretically generate buttressing is through hoop stresses (Morland and Zainuddin, 1987; Pegler and Worster, 2012, 2013). Hoop stresses are the viscous resistance to lateral spreading in a diverging flow. They act perpendicular to the flow direction and thickness gradient, and must be overcome in order for the flow to diverge. Therefore, along-flow extension is reduced in comparison with the equivalent $2 \mathrm{D}$ non-diverging case (see the Theory section below for a full explanation).

Morland and Zainuddin (1987) considered the potential of an ice shelf bordering the whole of the Antarctic Ice Sheet to provide buttressing via hoop stresses. This geometry had an origin at the centre of the continent and a radius of curvature corresponding to the average distance to the ice-sheet grounding line. They concluded that at this large radius of curvature the effect 

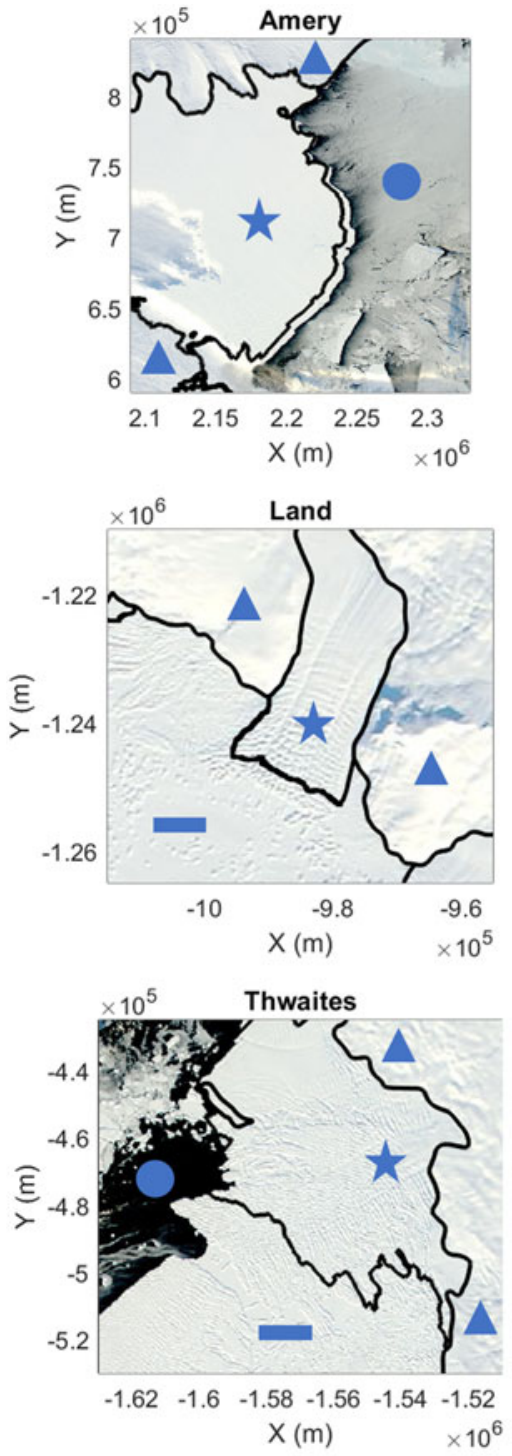

ig. 1. Worldview imagery of Amery, Fimbul, Land, Mertz, Thwaites and Totten ice shelves showing the extent of the laterally confined and unconfined regions of each ice shelf along with sea ice cover in April 2009. The grounding line and ice-ocean boundary are denoted by a black line, with regions of grounded ice, ice shelf, open ocean and sea ice denoted with symbols shown in key. Coordinates are given in WGS 84/Antarctic Polar Stereographic, with origin at the South Pole.
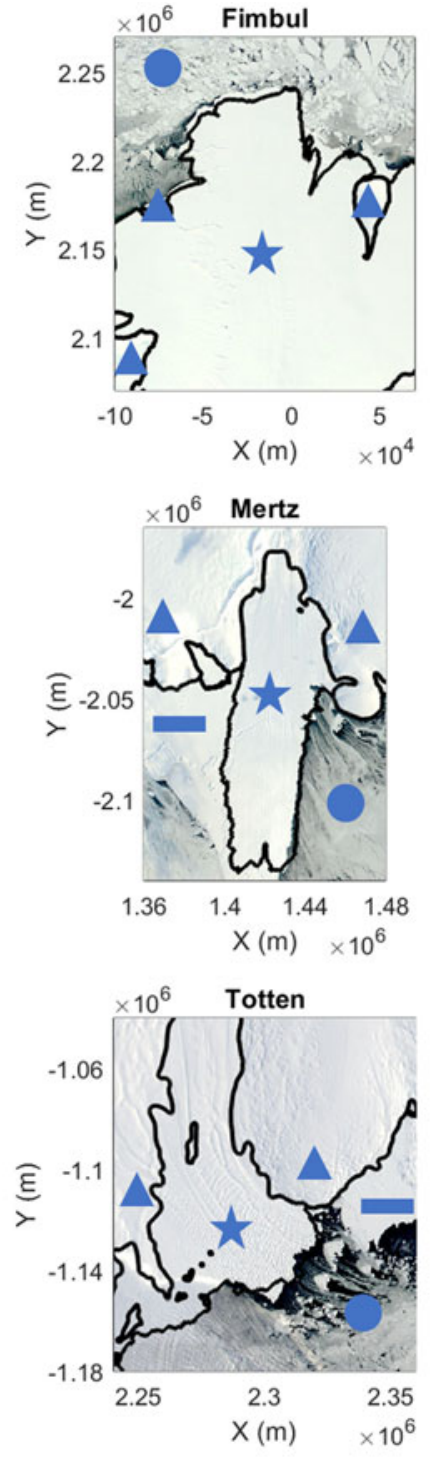

\section{$\Delta$ Groundedice $\quad \star$ Ice shelf $\quad$ Sea ice Ocean}

of buttressing from hoop stresses would be insignificant. They overlooked the fact that it is possible for individual ice shelves to have a much smaller radius of curvature as they leave the lateral confinement of final pinning points. However, observations of unconfined ice shelves in Antarctica indicate that ice shelves do not advance large distances into open ocean. This raises two questions: Do unconfined Antarctic ice shelves provide buttressing? Can hoop stresses allow ice shelves to regrow or advance beyond lateral confinements?

We build on results from theoretical work (Morland and Zainuddin, 1987; Pegler and Worster, 2012, 2013) and fluidmechanical laboratory experiments (Pegler and Worster, 2012, 2013) that demonstrate how ice-shelf hoop stresses can provide buttressing. We present the theory, from Morland and Zainuddin (1987), Pegler and Worster (2012, 2013), modify this for application to downstream-unconfined sections of ice shelves and explore the controls on the magnitude of buttressing using idealised examples. Using these theoretical tools we analyse the flow field of present-day unconfined sections of Antarctic ice shelves. We infer that in general these areas have low effective viscosity, most probably due to the high density of fractures within these regions, and as such are unable to sustain the high azimuthal stresses required to generate significant buttressing.
However, where ice shelves are additionally stabilised by sea ice, it appears the shelf has higher effective viscosity and azimuthal stresses can be generated to provide buttressing. This suggests that sea ice may prevent an ice tongue from collapsing and potentially allows it to advance.

\section{Theory: buttressing and hoop stresses}

The theory of hoop-stress buttressing has been presented previously by Morland and Zainuddin (1987), Pegler and Worster (2012, 2013). Here we present a consolidated version of this, with modification for application to the analysis of geophysical data from Antarctic ice shelves. The stresses within an ice shelf can be approximated using the Shallow Shelf Approximation (Morland, 1987; MacAyeal, 1989; Pegler and others, 2012), under the assumption of small gradients in ice thickness, such that the $2 \mathrm{D}$ depth-integrated horizontal force-balance is

$$
\nabla \mu H(\nabla \cdot \mathbf{u})+\nabla \cdot(\mu H \mathbf{e})=\frac{\rho g^{\prime}}{2} H \nabla H .
$$

Here $\nabla$ is the horizontal component of the gradient tensor, $\mu$ is the effective viscosity given by Glen's Flow Law, $H$ is the ice-shelf 
thickness, $\mathbf{u}$ is the horizontal component of the ice velocity, $\mathbf{e}$ is the strain-rate tensor, $\rho$ is the density of ice and $g^{\prime}$ is the reduced acceleration due to gravity. $\left(g^{\prime}=\left(1-\left(\rho / \rho_{w}\right)\right) g\right.$, with $\rho_{w}$ the density of seawater and $g$ the full acceleration due to gravity.) The first term on the left hand side (LHS) is the horizontal gradient in the vertically-integrated isotropic stress (or pressure) within the ice shelf, while the second term on the LHS is the divergence of the vertically-integrated deviatoric stress. The sum of these terms is balanced by the horizontal gradient in the vertically-integrated hydrostatic pressure difference between the ice and the ocean, which acts to drive ice flow in the direction of decreasing $H$.

We now consider three fundamental geometries of ice-shelf flow; a one-dimensional flowline, a laterally-confined ice shelf and a non-confined radially-spreading ice shelf.

\subsection{Base case: 1D flowline model - no buttressing}

First consider a simple one-dimensional approximation to an ice shelf with the domain aligned along a flowline. This simple case has been considered by many previous authors (e.g. Schoof, 2007; Robison and others, 2010) and we include it here as the first-order representation of an ice shelf. Here ice-shelf thickness and velocity vary in one dimension only (Fig. 2a). In this case, the horizontal force-balance Eqn (1) reduces to

$$
4 \frac{\partial}{\partial x}\left(\mu H \frac{\partial u}{\partial x}\right)=\rho g^{\prime} H \frac{\partial H}{\partial x}
$$

with $x$ aligned in the flow direction. This equation can be integrated along the length of the shelf, from the calving front, $x_{C}$ back to any point within the ice shelf, $x_{i}$, (most commonly the grounding line, $x_{G}$ ) to determine the depth-integrated horizontal stress at that point,

$$
\left.\mu H \frac{\partial u}{\partial x}\right|_{x_{i}}=\left.\mu H \frac{\partial u}{\partial x}\right|_{x_{C}}+\left.\frac{\rho g^{\prime}}{8} H^{2}\right|_{x_{i}}-\left.\frac{\rho g^{\prime}}{8} H^{2}\right|_{x_{C}},
$$

where in each term variables are evaluated at $x_{C}$ or $x_{i}$ as denoted by the vertical bar to the right of each term. The depth-integrated horizontal stress at the calving front is equal to the hydrostatic pressure difference between the ice and the ocean

$$
\left.\mu H \frac{\partial u}{\partial x}\right|_{x_{C}}=\left.\frac{\rho g^{\prime}}{8} H^{2}\right|_{x_{C}}
$$

Therefore, the two terms cancel in Eqn (3), giving

$$
F=\left.\mu H \frac{\partial u}{\partial x}\right|_{x_{i}}=\left.\frac{\rho g^{\prime}}{8} H^{2}\right|_{x_{i}}=F_{0} .
$$

The extensional stress at point $x_{i}$ in the presence of this $1 \mathrm{D}$ ice shelf is equivalent to the extensional stress felt in the absence of the shelf. We consider this to be the base state in which no buttressing is generated by the ice shelf, and hence denote the depth-integrated stress $F_{0}$. The following two sections describe fundamental ice-shelf geometries that generate buttressing.

\subsection{Laterally confined ice shelf - shear-stress buttressing}

Consider an ice shelf laterally confined within a parallel embayment. Ice flow is parallel to the side walls, aligned in the $x$-direction only, with $y$ aligned perpendicular to flow. The iceshelf thickness, $H$, is uniform across the width of the shelf (i.e. $H(x, y) \equiv H(x)$ ) (Pegler and others, 2013; Kowal and others, 2016; Pegler, 2016; Wearing, 2016; Haseloff and Sergienko,
2018), as shown in Figure 2b. The horizontal force-balance Eqn (1) reduces to

$$
4 \frac{\partial}{\partial x}\left(\mu H \frac{\partial u}{\partial x}\right)+\frac{\partial}{\partial y}\left(\mu H \frac{\partial u}{\partial y}\right)=\rho g^{\prime} H \frac{\partial H}{\partial x} .
$$

The additional term on the LHS is due to shear within the shelf, induced by friction or no-slip at the side walls of the embayment. Integrating along the length of the shelf

$$
\begin{gathered}
{\left[\mu H \frac{\partial u}{\partial x}\right]_{x_{i}}^{x_{C}}=\int_{x_{i}}^{x_{C}}\left[\frac{\rho g^{\prime}}{4} H \frac{\partial H}{\partial x}-\frac{1}{4} \frac{\partial}{\partial y}\left(\mu H \frac{\partial u}{\partial y}\right)\right] \mathrm{dx}} \\
\Rightarrow F=\left.\mu H \frac{\partial u}{\partial x}\right|_{x_{i}}=F_{0}+\int_{x_{i}}^{x_{C}} \frac{1}{4} \frac{\partial}{\partial y}\left(\mu H \frac{\partial u}{\partial y}\right) \mathrm{dx} \\
=F_{0}-F_{\text {shear }} \\
\Rightarrow F_{\text {shear }}=-\int_{x_{i}}^{x_{C}} \frac{1}{4} \frac{\partial}{\partial y}\left(\mu H \frac{\partial u}{\partial y}\right) \mathrm{dx} .
\end{gathered}
$$

In this case, the depth-integrated horizontal stress, $F$, is reduced in comparison with the base case because of buttressing from shear stress, $F_{\text {shear }}$.

The level of ice-shelf buttressing can be quantified using the buttressing number (Gudmundsson, 2013),

$$
B_{N}=\frac{F_{0}-F}{F_{0}}
$$

$B_{N}$ is the difference between the depth-integrated horizontal stress in the absence of an ice shelf, $F_{0}$, and the actual depth-integrated horizontal stress $F$, normalised by $F_{0}$. While the value of $F_{0}$ is the same in all directions, the orientation of $F$ must be defined. At the grounding line, the depth-integrated horizontal stress of interest acts perpendicular to the grounding line. In this case, with $F$ aligned perpendicular to the grounding line, $B_{N}=0$ signifies that there is no buttressing generated by the shelf, while $B_{N}=1$ implies that the downstream ice shelf provides complete buttressing such that extensional stress is zero.

The buttressing number can also be used to determine buttressing within the ice shelf. In this work we consider buttressing in the flow direction (flow buttressing Fürst and others (2016)) and calculate the difference between $F$ and $F_{0}$, where $F$ is aligned with flow. In contrast, Fürst and others (2016) used the orientation and magnitude of the depth-integrated second principal stress (SPS) to define the maximum buttressing number within the ice shelf. The SPS is often not aligned in the flow direction (much of the time it is aligned perpendicular to the flow). If a section of the shelf is removed via calving, the flow and stress field within the shelf would be altered. Therefore, although $B_{N}$ aligned with the SPS within the ice shelf may be a useful way to choose which sections of an ice shelf to remove in a numerical model, the corresponding value of $B_{N}$ does not signify the magnitude of buttressing generated to resist ice flow upstream. As such, in Fürst and others (2016) the maximum buttressing number varies between each section of passive ice. It is an open question whether a buttressing number is an effective way to measure buttressing within ice shelves, where flow and stress fields may be complex. We avoid this issue by considering simple geometries where the flow is perpendicular to the grounding line, such that buttressing in the flow direction acts across the grounding line. We use the flow buttressing number throughout the following analysis and hereafter refer to this as the buttressing number, $B_{N}$. 


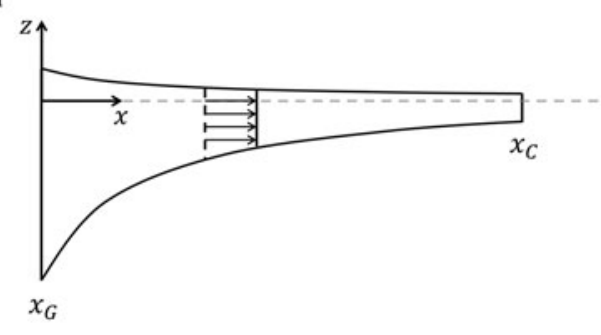

C

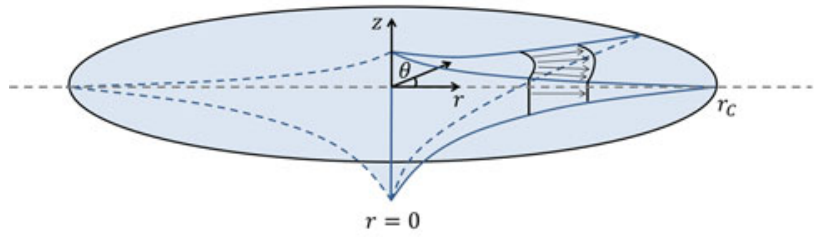

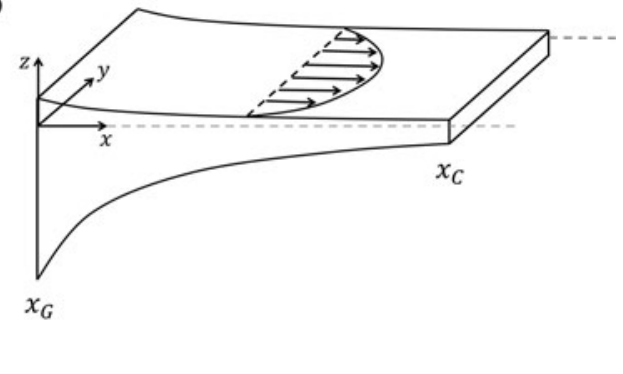

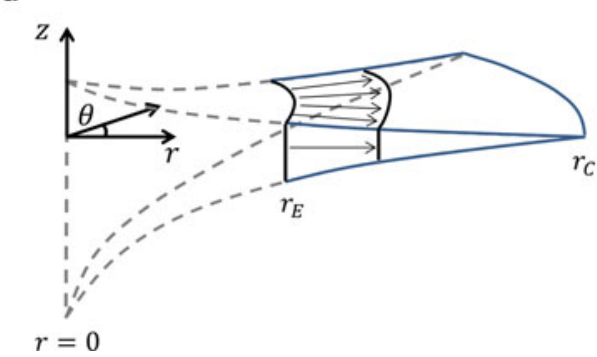

Fig. 2. Fundamental ice-shelf geometries: (a) 1-D flowline. (b) Laterally confined ice shelf in a parallel embayment. (c) Axisymmetrical radially-spreading shelf. (d) Sector of an axisymmetric radially-spreading shelf, which in plan view forms an annulus.

\subsection{Unconfined radially-spreading ice shelf - hoop-stress buttressing}

The third fundamental configuration we consider is an unconfined ice shelf, which is able to spread laterally in two directions. The simplest idealised example of this is an ice shelf spreading from a point source. In cylindrical coordinates, with the source at the origin, the flow is radially outwards and axisymmetric (symmetric with respect to rotation around the vertical axis) (Fig. 2c). This type of geometry has been considered previously by Morland and Zainuddin (1987), Pegler and Worster (2012, 2013). With the radial coordinate, $r$, aligned in the flow direction and no variation in flow azimuthally (with respect to rotation about the vertical axis), the force-balance Eqn (1) becomes

$$
2 \frac{\partial}{\partial r}\left(\mu H\left(2 \frac{\partial u}{\partial r}+\frac{u}{r}\right)\right)+2 \mu H \frac{\partial}{\partial r}\left(\frac{u}{r}\right)=\rho g^{\prime} H \frac{\partial H}{\partial r} .
$$

The full derivation of this equation is given in Appendix A. The first term on the LHS is the radial derivative of the vertically-integrated isotropic stress and along-flow (radial) deviatoric stress (identical to the LHS of Eqn (2), but in cylindrical coordinates). The second term on the LHS of (12) is the depth-integrated radial gradient in the azimuthal strain rate, multiplied by the effective viscosity. This is the additional component from the divergence of the strain-rate tensor, which emerges in cylindrical coordinates, and is required to ensure the flow is incompressible when the shelf flows radially (Appendix A). Equation (12) can be integrated radially back from the ice front $\left(r_{C}\right)$ to a point in the ice shelf $\left(r_{i}\right)$ to give

$$
\begin{aligned}
F=\left.\frac{\mu H}{2}\left(2 \frac{\partial u}{\partial r}+\frac{u}{r}\right)\right|_{r_{i}} & =\left.\frac{\rho g^{\prime}}{8} H^{2}\right|_{r_{i}}+\int_{r_{i}}^{r_{C}} \frac{\mu H}{2} \frac{\partial}{\partial r}\left(\frac{u}{r}\right) \mathrm{dr}, \\
& =F_{0}-F_{\text {hoop }}, \\
F_{\text {hoop }} & =-\int_{r_{i}}^{r_{C}} \frac{\mu H}{2} \frac{\partial}{\partial r}\left(\frac{u}{r}\right) \mathrm{dr},
\end{aligned}
$$

$$
=-\int_{r_{i}}^{r_{C}} \frac{\mu H}{2 r}\left[\frac{\partial u}{\partial r}-\frac{u}{r}\right] \mathrm{dr}
$$

as in Pegler and Worster (2012). Therefore, hoop stresses make a positive contribution to buttressing where the azimuthal extension $u / r$ exceeds the radial extension $\partial u / \partial r$. Conversely, negative hoop-stress contributions are made where azimuthal extension is less than radial extension. When the hoop-stress buttressing is negative the viscous resistance to azimuthal extension acts to increase radial extension and pulls ice downstream. From the integrand it is clear that the magnitude of hoop-stress contributions increases for increasing effective viscosity $(\mu)$ and thickness $(H)$, but decreases with a radial distance.

Physically, hoop stresses act as the viscous resistance to spreading in the azimuthal direction as the ice shelf flows radially. For an axisymmetric shelf there is no azimuthal thickness gradient, so azimuthal spreading must be induced by the radial thickness gradient. As with the shear-stress case, the integrated effect of this viscous deformation back from the ice front produces buttressing and may reduce the extensional stress at the grounding line.

For an axisymmetric ice shelf extending to infinity, Pegler and Worster (2012) established analytically an upper bound for the radius of curvature at the grounding line that would provide positive buttressing; $L \equiv\left(\mu Q_{0} / 2 \pi \rho g^{\prime} H_{0}^{2}\right)^{1 / 2}$, where $H_{0}$ and $Q_{0}$ are the ice thickness and flux at the grounding line. Pegler and Worster (2012) estimated that for a typical ice shelf $L \approx 5 \mathrm{~km}$. Furthermore, for ice shelves with radius of curvature at the grounding line greater than $6 L$, hoop stresses provided negative buttressing - generating additional extension at the grounding line. This analytical work was accompanied by laboratory-scale analogue experiments.

Here we consider hoop-stress buttressing generated by unconfined sections of ice shelves of finite length, found where ice shelves flow out past lateral pinning points, such as Amery and Fimbul Ice Shelves, Figure 1. The downstream sections of these ice shelves can be approximated as sectors of an annulus with radius of curvature at the upstream boundary $\left(r_{E}\right)$ dependent on the lateral divergence of the flow, Figure 3. With no shear against lateral boundaries, these sections can be 


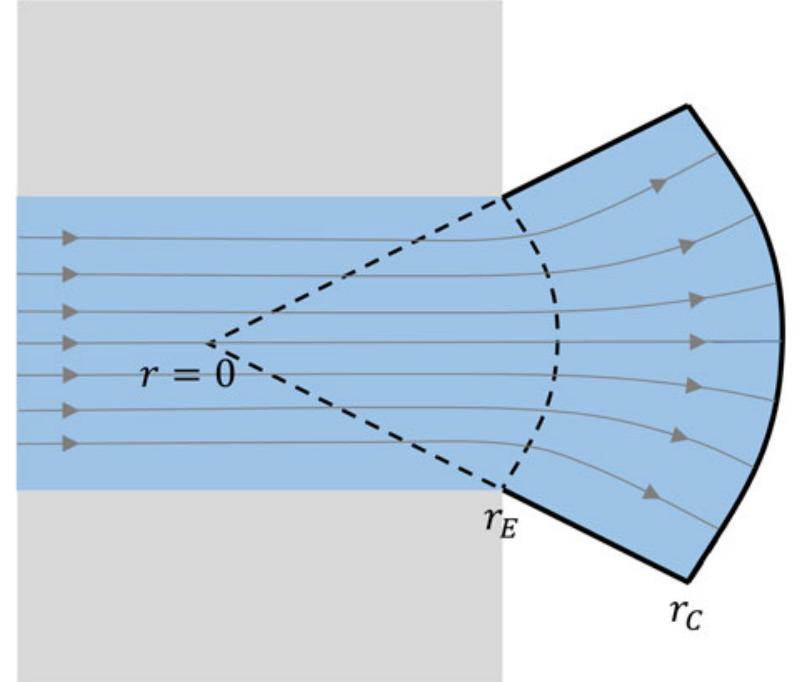

Fig. 3. Approximating an unconfined section of an ice shelf as an annulus diverging from an imaginary origin $(r=0)$. The ice shelf flows out from an area of confinement and diverges into open ocean. The radius of curvature at the exit of the embayment $\left(r_{E}\right)$ and at the calving front $\left(r_{C}\right)$ are labelled.

approximated as azimuthally symmetric. We first consider some idealised examples, determining the magnitude of hoop-stress buttressing produced in each case. Then, using geophysical, data we assess hoop-stress buttressing in unconfined sections of Antarctic ice shelves.

\section{Idealised examples}

We model the unconfined downstream section of an ice shelf, with geometry resembling a sector of an annulus in plan-view, as shown in Figures $2 \mathrm{~d}$ and 3 . We assume there is no azimuthal variation in flow or ice thickness so consider a radial flowline. We denote an imaginary origin, $r=0$, from which we determine positions $r_{E}$ and $r_{C}$, as the radius of curvature at the upstream boundary (exit of the embayment) and the ice front respectively. We impose a fixed ice thickness and velocity at $r_{E}$, and balance extensional stress with the vertically-integrated hydrostatic pressure difference between the ice and ocean at the calving front $r_{C}$. We assume a Glen's Flow Law rheology

$$
\mu=\frac{1}{2} A^{-1 / n} \mathbf{e}_{I I}^{(1-n) / n},
$$

with rate factor $A=A_{-10}=3.5 \times 10^{-25} \mathrm{~s}^{-1} \mathrm{~Pa}^{-3}$, appropriate for ice at $-10^{\circ} \mathrm{C}$ (Cuffey and Paterson, 2010), $n=3$ the flow-law exponent and $\mathbf{e}_{I I}$ the second invariant of the strain-rate tensor. Simulations are initiated with an ice shelf of uniform thickness. We solve Eqn (12) numerically using successive over relaxation (Young, 1971) to determine the radial velocity and then evolve the thickness of the ice shelf according to the continuity equation

$$
\frac{\partial H}{\partial t}+H \frac{\partial u}{\partial r}+u \frac{\partial H}{\partial r}=b
$$

where $b$ is the net specific mass balance; the sum of surface accumulation and ablation, and basal melting and freeze-on. The thickness is evolved forward in time using an explicit timestepping scheme until a steady state is reached. We calculate the buttressing from hoop stresses produced in the shelf downstream of $r_{E}$. For these idealised examples we set $b=0$.

\subsection{Example 1}

Figure 4 shows the steady-state results for an ice shelf of length $50 \mathrm{~km}$, with radius of curvature at the upstream boundary of $70 \mathrm{~km}$. The input thickness is $400 \mathrm{~m}$ and the input velocity is $500 \mathrm{~m} \mathrm{a}^{-1}$. For an angle of divergence of $10^{\circ}$, the shelf diverges from a width of 20 to $40 \mathrm{~km}$ along its length. Throughout the shelf the azimuthal strain rate is greater than the radial strain rate, implying a positive hoop-stress contribution everywhere. This can been seen from the increase in the buttressing number back from the calving front to $r_{E}$ where it reaches 0.2 ; i.e. $20 \%$ of the hydrostatic stress is balanced by hoop stresses.

\subsection{Example 2}

A similar shelf is shown in Figure 5, however the radius of curvature at the upstream boundary has been increased to $400 \mathrm{~km}$ and the shelf is now $100 \mathrm{~km}$ long. Due to the large radius of curvature the width of the shelf only increases from 140 to $170 \mathrm{~km}$ along its length, for an angle of divergence of $10^{\circ}$. Figure $5 \mathrm{c}$ shows that the azimuthal strain rate is greater than the radial strain rate in the downstream section of the shelf $(>435 \mathrm{~km})$ only. This leads to a transition from positive to negative hoop-stress buttressing contributions in the upstream direction. The peak in buttressing number is just downstream of this transition (Fig. 5e) because the ice is thinner and the driving stress (hydrostatic pressure difference between ice and ocean) decreases downstream. In this case the buttressing number at the upstream boundary $\left(r_{E}=400 \mathrm{~km}\right)$ is very small and the shelf provides insignificant buttressing via hoop stresses $(<1.5 \%)$.

\subsection{Positive and negative hoop-stress contributions}

For steady-state ice shelves the sign of the hoop-stress buttressing contribution is dependent on the local ice-shelf thickness profile. For a radially spreading shelf, with angle of divergence $\theta$ at the origin, the flux at radius $r$ in the steady state is

$$
\theta r u(r) H(r)=q_{0}+\frac{1}{2} b \theta r^{2},
$$

where $q_{0}$ is the input flux at $r=0$ and the second term on the RHS is the net mass gain/loss between the origin and $r$, due to surface or basal processes. The ice must thin in the downstream direction and we approximate the local ice thickness profile as

$$
H \approx \tilde{H} r^{-a},
$$

where the exponent $a$ is dependent on the local curvature of the ice thickness and in turn the deformation of the shelf at this point. Therefore the radial velocity takes the form

$$
u(r)=\frac{q_{0}+\frac{1}{2} b \theta r^{2}}{\theta \tilde{H} r^{1-a}} .
$$

This can be used to determine the radial and azimuthal strain rates, such that hoop-stress buttressing contributions are positive when

$$
\begin{gathered}
\frac{u}{r}>\frac{\partial u}{\partial r} \\
\Rightarrow \quad(2-a)\left(q_{0}+b \theta \frac{r^{2}}{2}\right)>b \theta r^{2-a} .
\end{gathered}
$$

In the case of $b=0$, this reduces to $a<2$. Therefore, in the steady-state with $b=0$, at locations where the ice thickness 

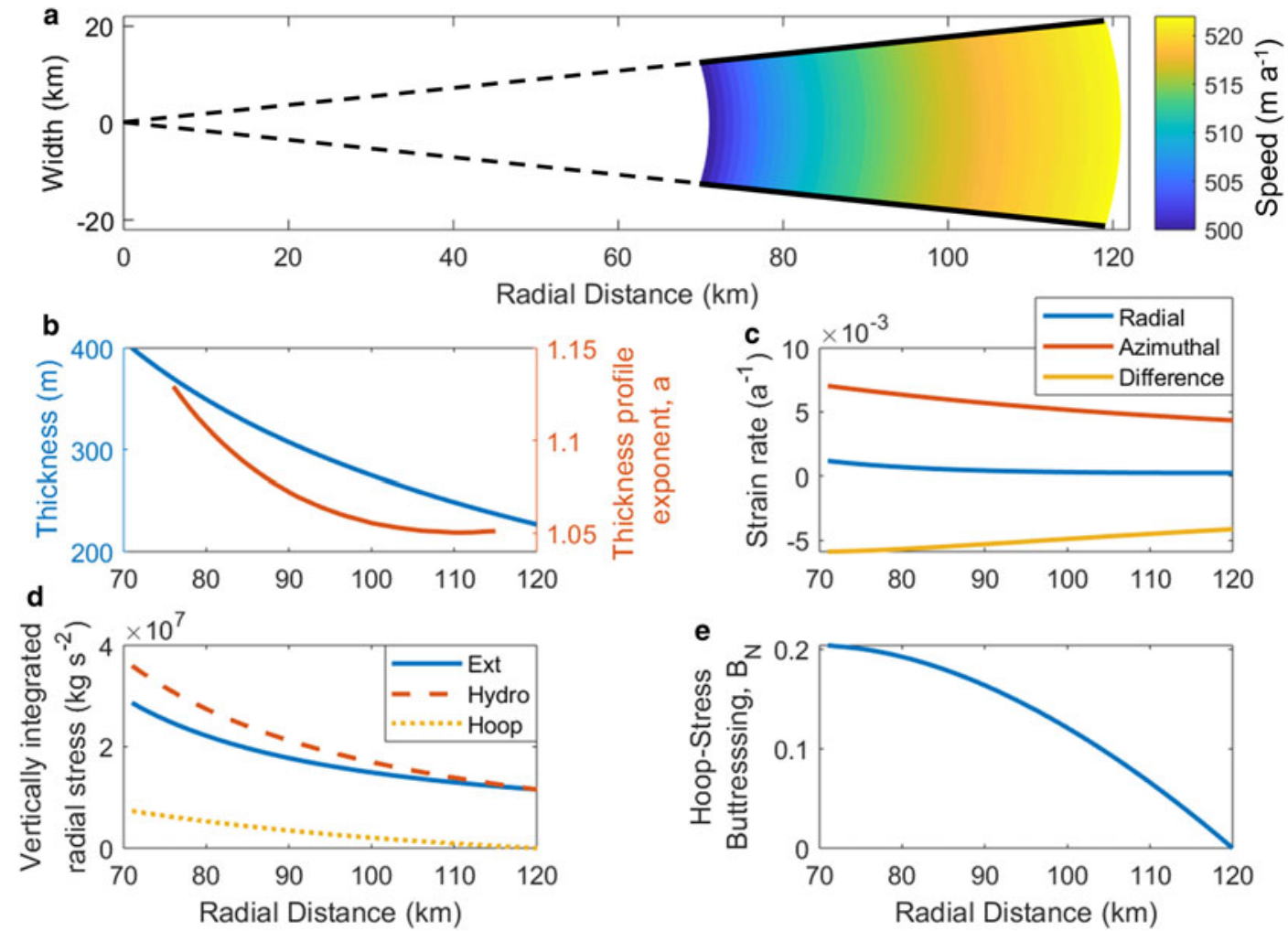

Fig. 4. Example of an idealised ice shelf with rate factor $A_{-10}$. The radius of curvature at the upstream boundary is $70 \mathrm{~km}$ and shelf has a length of $50 \mathrm{~km}$. (a) Ice speed. (b) Ice-shelf thickness profile (blue) and value of the local thickness-profile exponent, $a$ (red), for function $H=\tilde{H} r^{-a}$, calculated at each point by fitting the function to an 11-km interval around each point. (c) Radial strain rate (blue), azimuthal strain rate (red), difference; radial minus azimuthal strain rate (orange). (d) Depth-integrated stresses; radial extension (blue), hydrostatic driving stress (red dashed) and hoop stress (dotted yellow). (e) Buttressing number along the length of the shelf.
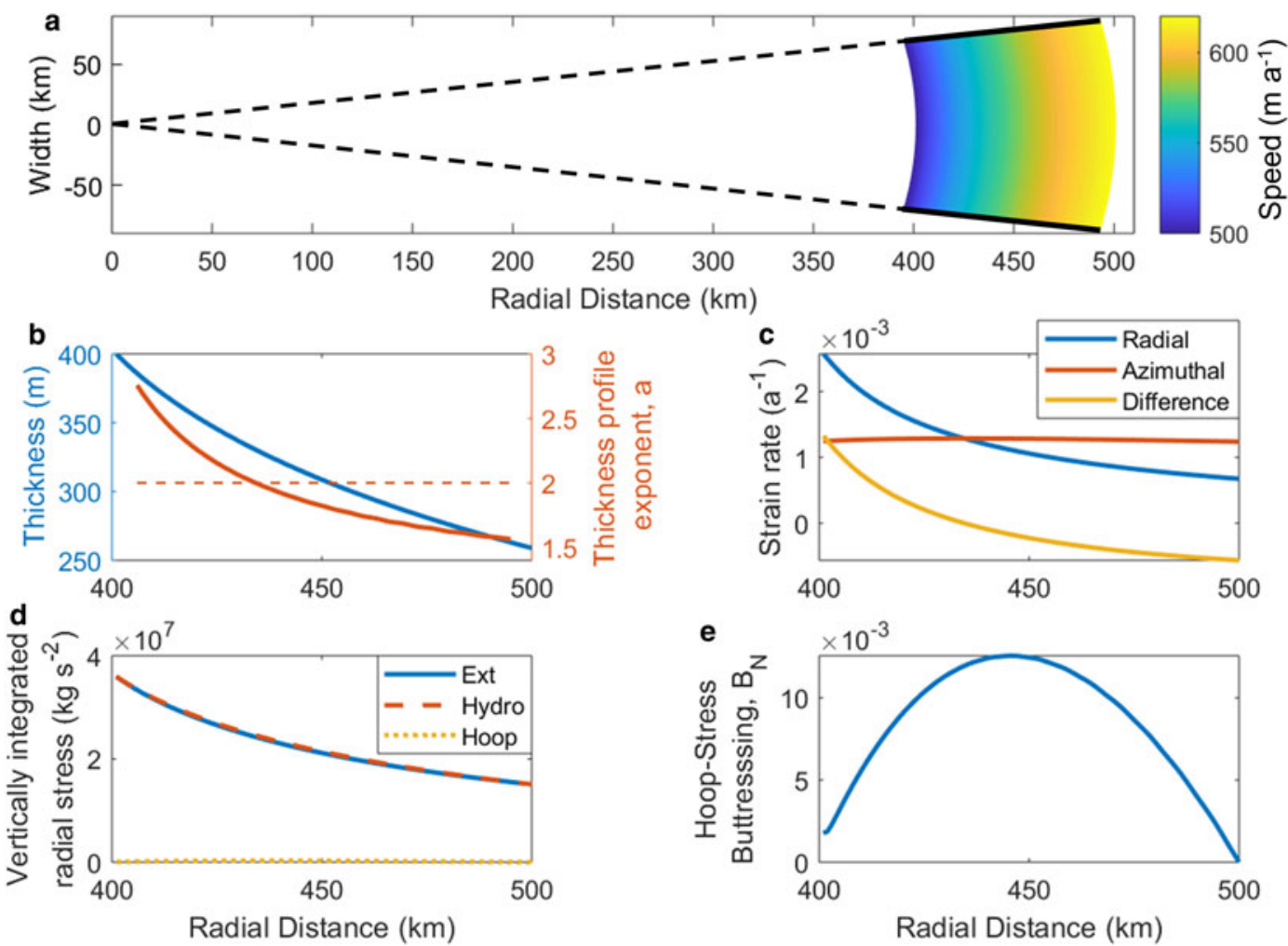

Fig. 5. Same as Figure 4, but with a $400 \mathrm{~km}$ radius of curvature at the upstream boundary and shelf of $100 \mathrm{~km}$ in length. Hoop-stress buttressing remains positive throughout the length of the shelf. However, negative hoop-stress contributions are made in the upstream section and hence the peak in hoop-stress buttressing is located at $r \approx 440 \mathrm{~km}$. 

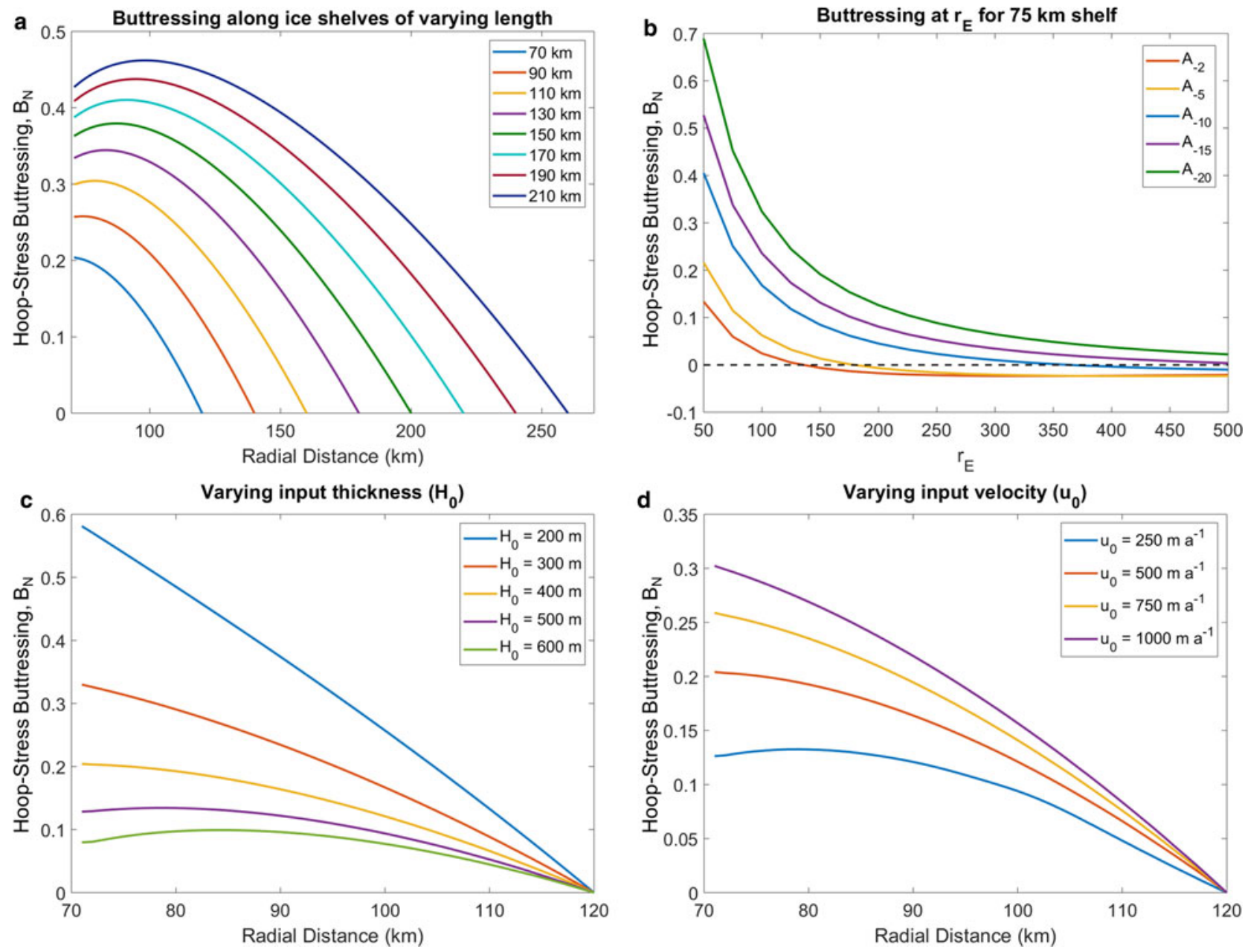

Fig. 6. Varying parameters in the idealised model. Each panel shows the buttressing number (vertical axis): (a) along the length of the shelf when increasing the shelf length; (b) at the upstream boundary $\left(r_{E}\right)$ of a $75 \mathrm{~km}$ shelf, when the radius of curvature at the upstream boundary $\left(r_{E}\right.$; horizontal axis) and rate factor $\left(A_{X}\right.$; coloured curves) are varied; (c) and (d) along the length of the shelf for varying input thicknesses (fixed velocity $500 \mathrm{~m} \mathrm{a}^{-1}$ ) (c) and varying input velocities (fixed thickness $400 \mathrm{~m})(\mathrm{d})$.

profile can be approximated by $\tilde{H} r^{-a}$ with $a<2$, positive hoop-stress buttressing is generated. The exponent for the local ice-thickness profile, $a$, is calculated at each point along the shelf using the MATLAB curve fitting function fit, which uses the ice thickness within an $11 \mathrm{~km}$ interval centred at each point to determine $a$. The spatially-evolving value of $a$ is shown in Figure $5 b$, where there is a transition from $a>2$ to $a<2$ at $r \approx 435 \mathrm{~km}$, where the magnitude of the radial and azimuthal strain rates are equal. For $a>2$ hoop-stress buttressing contributions are negative. In contrast, in Figure $4 \mathrm{~b}$, hoop-stress contributions are positive throughout the length of the shelf and $a<2$ everywhere.

\subsection{Varying parameters}

As identified by Pegler and Worster (2012), the magnitude of buttressing from hoop stresses is dependent on the radius of curvature at $r_{E}$, the shelf viscosity, the input thickness and input velocity. In Figure 6 these parameters, along with the length of the ice shelf, are varied to assess the impact on buttressing.

As the length of a shelf is increased the buttressing number at $r_{E}$ increases (Fig. 6a). However, the magnitude of this increase decreases with shelf length, and the peak in buttressing number is shifted downstream. This implies that hoop-stress buttressing increases at a reduced rate in comparison with the driving hydrostatic pressure as the ice thickens (it is the ratio of hoop-stress buttressing to driving stress that determines the buttressing number). It may also suggest that the upstream section of the shelf begins to produce negative hoop-stress contributions. However, further assessment shows that in these cases the azimuthal extension remains larger than radial extension and the thickness-profile exponent $a$ remains less than 2. Therefore, hoop-stress contributions remain positive.

Figure $6 \mathrm{~b}$ shows the effects of varying both the radius of curvature at the upstream boundary and the rate factor for an ice shelf of fixed length $(75 \mathrm{~km})$. Buttressing is reduced as the radius of curvature at the upstream boundary, $r_{E}$, increases and the lateral divergence of the shelf decreases. There is a transition to slightly negative buttressing once $r_{E}$ increases past a critical point. This is dependent on the rate factor in the ice rheology. For decreasing rate factor, and therefore increasing effective viscosity, hoop stresses provide greater buttressing.

Figures $6 \mathrm{c}$ and $\mathrm{d}$ show the buttressing number for varying input fluxes at the upstream boundary. Increasing the input thickness and maintaining input velocity leads to reduced buttressing. This is because thicker ice produces a larger driving stress, which generates large radial strain rates. Conversely, for a fixed input thickness and increased input velocity, buttressing increases. This is because the hydrostatic driving stress remains the same, but the azimuthal strain rate increases like $u / r$. 


\section{Hoop-stress buttressing from Antarctic ice shelves}

We now use this theory to approximate the magnitude of hoopstress buttressing generated by unconfined Antarctic ice shelves.

\subsection{Method}

We approximate the unconfined section of each ice shelf as an annulus using ice-surface velocities and the divergence of flowlines to determine the geometry. We then model the ice flow within the annulus, as in the previous section, to estimate the hoop-stress contribution to buttressing. The process is detailed in Appendix B and summarised here. A geometric argument is used to determine upstream, downstream and lateral boundaries along with the radius of curvature. We used a Gaussian smoothed version (Wearing and others, 2015; Wearing, 2016) of MEAsUREs V2 surface velocity data (Rignot and others, 2011, 2017) and Bedmap2 ice thickness data (Fretwell and others, 2013).

Flowlines are used to identify the lateral extent of the spreading ice shelf once it leaves lateral confinement. We draw lines perpendicular to the approximate central flowline at the upstream and downstream extent of this unconfined region to mark the position of the upstream and downstream boundaries. We draw two additional lines connecting the outermost points of the upstream and downstream boundaries and extend them upstream until they intersect. This defines the imaginary origin and the radius of curvature at the upstream and downstream boundaries. The ice thickness and speed at the boundaries are determined by the mean along each boundary. Assuming steady state, we estimate the mean specific mass balance, $\bar{b}$, over the unconfined area of the shelf using the difference in flux across the upstream and downstream boundary.

Once the geometry, input flux and specific mass balance are known, we use the radial force-balance Eqn (12) and continuity Eqn (18) (with $b=\bar{b}$ ) to model the thickness profile, velocity field and hoop-stress buttressing. We begin with a uniform thickness ice shelf (equal to the average ice thickness at the upstream boundary) and the shelf is evolved to steady state. The process is repeated for three different rate factors in the rheological model, $A=A_{-2}, A_{-5}$ and $A_{-10}$, with subscripts denoting appropriate ice temperature in degrees Celsius (Cuffey and Paterson, 2010). The final ice thickness and speed profiles are compared to the data along six flowlines. The root mean square error (RMSE) is calculated between the model output and the flowline data, with the mean of the RMSEs used to determine which rheology provides the best fit. We restrict analysis to six ice shelves of varying sizes that clearly extend beyond lateral confinements: Amery, Fimbul, Land, Mertz, Thwaites and Totten.

Alternative approaches for determining hoop-stress buttressing may be possible. For example, using velocity data along streamlines to compute hoop-stress contributions directly. However, differentiating the often noisy data generates sharp fluctuations in strain rates, which impede interpretation of the results. (An outline of this method and some preliminary results are shown in the Supplementary Material (SM) and Wearing, 2016.) Alternatively, a formal inversion procedure could be used to simulate the stress field and assess hoop-stress buttressing. However, the simplicity of our approach aids our understanding of the controls on hoop-stress buttressing and our conclusions do not rely heavily on a fully resolved stress field.

\subsection{Results}

Figure 7 shows results from Amery Ice Shelf. The radius of curvature at the upstream boundary is approximately $r_{E}=150 \mathrm{~km}$, with a further $55 \mathrm{~km}$ of unconfined ice shelf downstream. The best fit to the flowline data of ice thickness and speed is achieved for an idealised ice shelf with rate factor $A_{-5}$ (Figs $7 \mathrm{~b}, \mathrm{c}$ ). Hoop-stress buttressing contributions are positive throughout the shelf; i.e. azimuthal strain is greater than radial strain (Fig. $7 \mathrm{~d}$, dashed curves for $\left.A_{-5}\right)$. For a weaker rheology, $A_{-2}$, this is not the case, with negative hoop-stress contributions in the upstream part of the shelf (Fig. $7 \mathrm{~d}$, dotted curves for $A_{-2}$ ). The buttressing number at the upstream boundary is approximately 0.04 . This relatively small buttressing number is due to the large radius of curvature at the upstream boundary and the low rate factor which leads to low effective viscosity.

The buttressing numbers from the upstream boundary, $r_{E}$, downstream to the calving front for each of the ice shelves considered are shown in Figure 8 with a complete set of plots for each ice shelf, as for Amery Ice Shelf in Figure 7, given in the SM (Figs S1S6). The buttressing number is shown for three rate factors $\left(A_{-2}\right.$, $A_{-5}$ and $\left.A_{-10}\right)$ with thick blue curves corresponding to results with the smallest mean RMSE between the model and the flowline velocity and thickness.

Fimbul Ice Shelf has a very large radius of curvature as it flows beyond the final lateral pinning points, $r_{E}=320 \mathrm{~km}$, and an unconfined shelf of $50 \mathrm{~km}$ in length. The buttressing number at the upstream boundary is approximately 0.04 , for rate factor $A_{-10}$, suggesting insignificant buttressing (Fig. 8b). This is largely due to the large radius of curvature, which implies low azimuthal spreading and therefore little buttressing despite colder and therefore more viscous ice.

Land Ice Shelf, Figure $8 \mathrm{c}$, is a relatively small ice shelf with an unconfined section of $8 \mathrm{~km}$ in length, and a radius of curvature of $32 \mathrm{~km}$ at the upstream boundary. Here it is unclear which rheological parameters provide the best fit to the data, as ice-shelf flow increases along all flowlines, but the ice thickness appears to thin along some and thicken along others (Figs S3b, c). This uncertainty leads to a large range in potential buttressing numbers at the upstream boundary between 0.04 and 0.15 . However, the lowest mean RMSE is achieved for rate factor $A_{-2}$, with buttressing 0.04 .

For Mertz Ice Tongue, Figure $8 \mathrm{~d}$, rate factors between $A_{-5}$ and $A_{-10}$ appear to be most appropriate (Figs S4 b, c). The smallest mean RMSE is obtained for $A_{-10}$ with a buttressing number at the grounding line of 0.09 , produced by a shelf of length $29 \mathrm{~km}$ and $r_{E}=101 \mathrm{~km}$.

For Thwaites Glacier Ice Shelf $\left(r_{E}=230 \mathrm{~km}\right.$ and length $\left.30 \mathrm{~km}\right)$ the best match between velocity, thickness and the idealised model is for ice with $A_{-2}$ (Fig. S5). However, this fit could be improved further with an even weaker rheology. This suggests the shelf is made up of very weak ice. This can also be inferred from the high density of visible surface fractures on the shelf Figure 1. In this case hoop-stress buttressing from the ice shelf is very small and potentially negative at the upstream boundary.

The best match between the idealised model and flowline data for Totten Ice Shelf is achieved for relatively warm ice temperatures; $A_{-2}, A_{-5}$, with RMSE values lowest for the ice flow speed and ice thickness respectively. This leads to buttressing numbers at the upstream boundary of between 0.01 and 0.03 .

\section{Discussion}

For most of the ice shelves analysed, except Mertz Ice Tongue (and possibly Land Ice Shelf), hoop-stress buttressing from the unconfined section of the ice shelf produces insignificant buttressing, with buttressing numbers less than 0.05 ; buttressing from hoop stresses balances less than $5 \%$ of the driving stress. This is due to weak rheology and large radii of curvature. None 

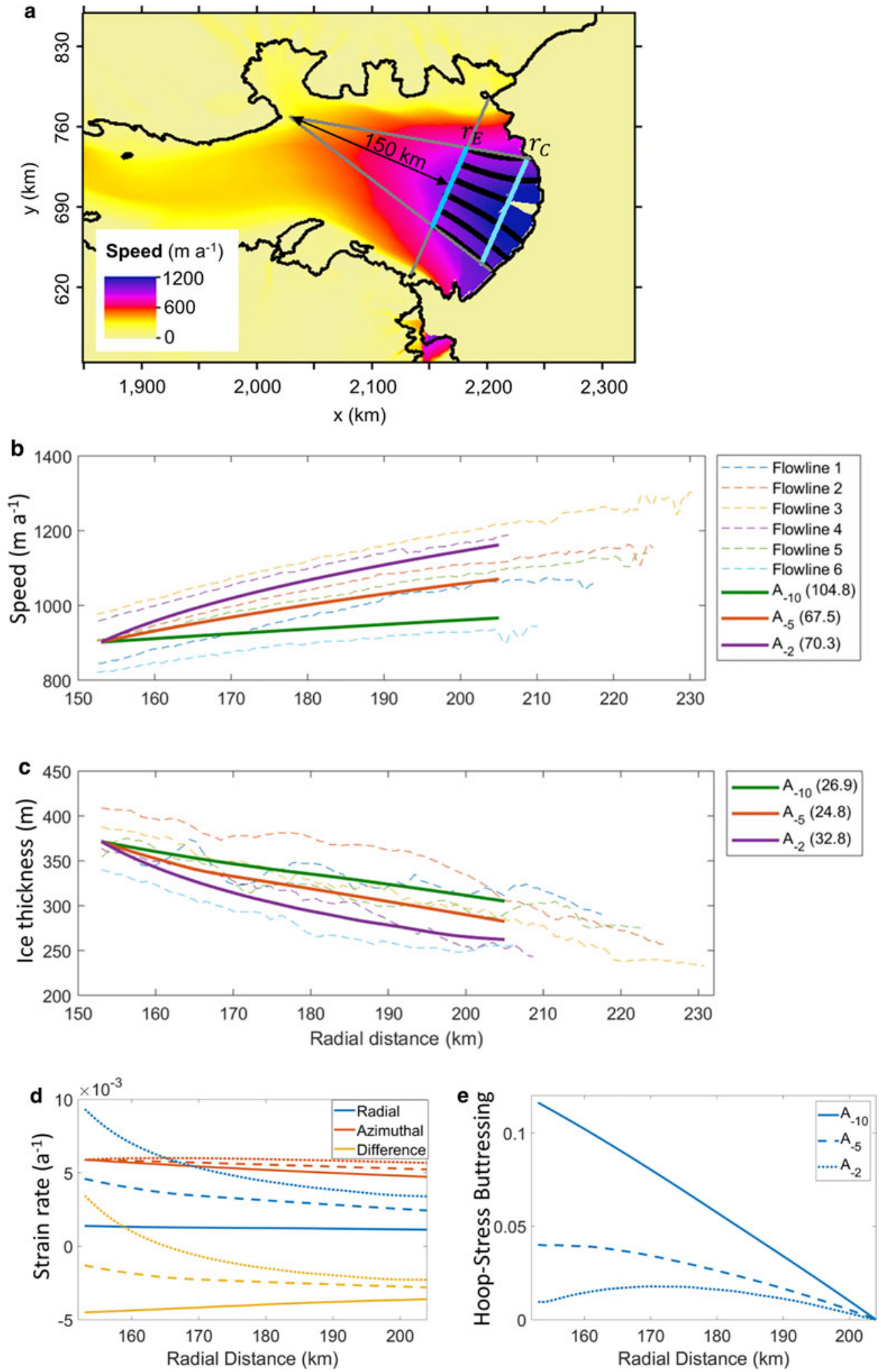

Fig. 7. Applying idealised model annulus to Amery Ice Shelf: (a) ice speed map with geometry of flowlines and upstream and downstream boundaries. (b) Flow speed along flowlines 1 - 6 (bottom to top in (a)) (dashed curves) with simulated speed (solid curves) at three rate factors $\left(A_{-2}, A_{-5}\right.$ and $A_{-10}$ ). (c) Same as (b) but for ice thickness. In both (b) and (c) the mean RMSE for each rate factor is given in the brackets in the legend. (d) Strain rates from model and (e) buttressing number along length of shelf. In (d) and (e); $A_{-2}$ (dotted), $A_{-5}$ (dashed) and $A_{-10}$ (solid).

of the ice shelves assessed produce negative hoop-stress buttressing, with the exception of Thwaites Ice Shelf, which potentially produces insignificant negative buttressing $(<0.5 \%)$. In the case of Amery and Totten ice shelves, the geometry of the divergent flow has the potential to provide hoop-stress buttressing of approximately $10 \%$ of the radial driving stress if the ice had a larger rate factor (i.e. $A_{-10}$ or more). In general, the rheological parameters that produce the best fit to geophysical data are appropriate for warm ice $\left(A=A_{-5}, A_{2}\right)$, with temperatures greater than would normally be expected for ice shelves (depth-averaged englacial temperatures are typically less than or equal to $-5^{\circ} \mathrm{C}$; Fig. S8). This suggests that the ice is 
Fig. 8. Buttressing number along the length of unconfined section of ice shelves: Amery, Fimbul, Land, Mertz, Thwaites and Totten. Buttressing numbers are shown for all rate factors, with bold blue curves, corresponding to the models with speed and ice thickness that best match data (the best match is different for speed and thickness in panel (f), so there are two blue curves). In the legend the mean RMSE for the speed (S) and ice thickness $(\mathrm{H})$ are shown in brackets for each rate factor. See Figures S1-S6 for full set of plots as in Figure 7.
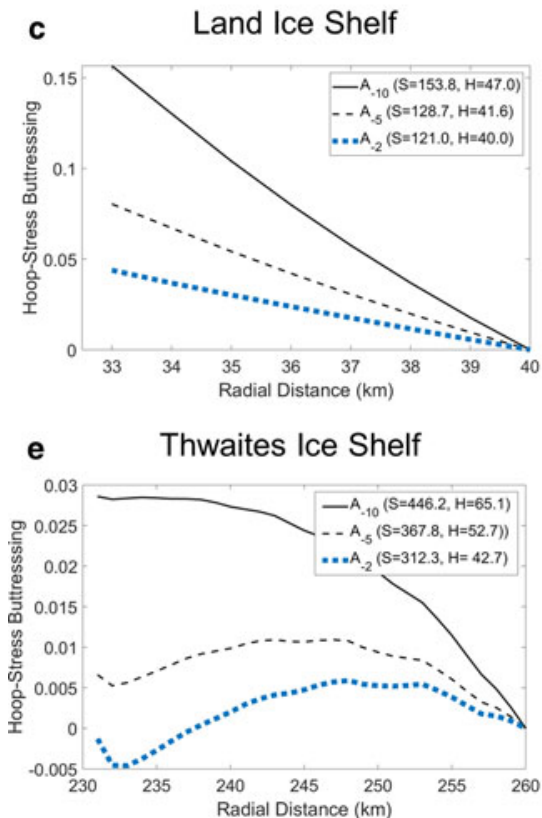

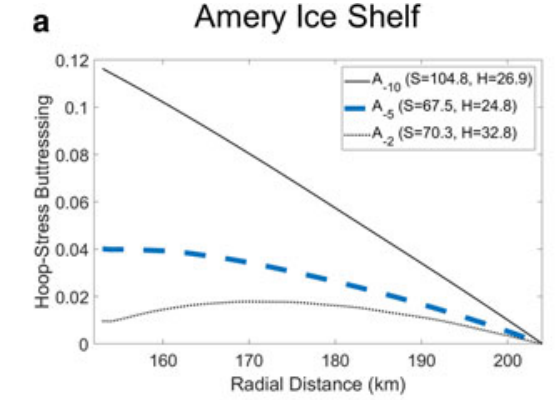

f

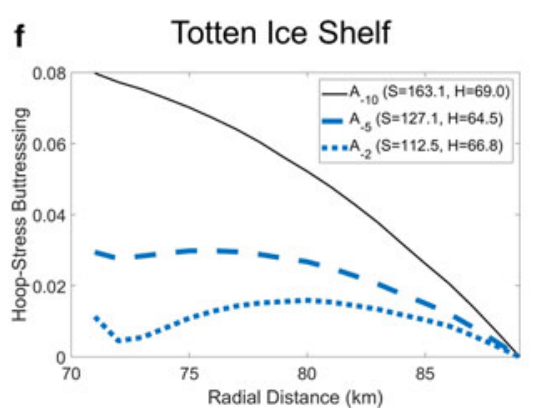

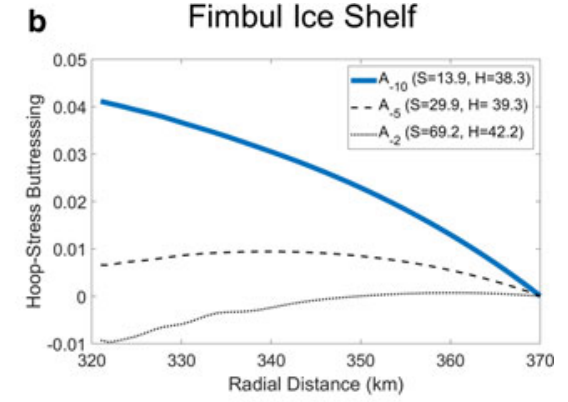

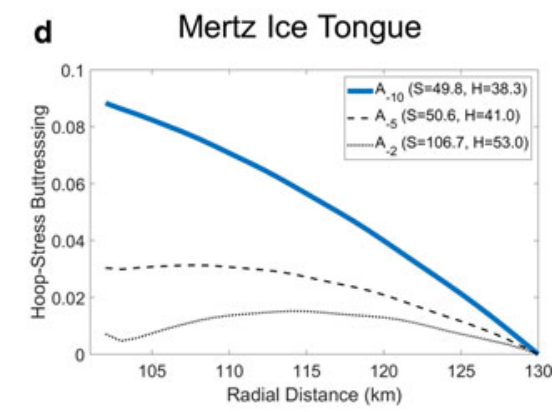

weakened by damage such as fracturing and crevasses (Borstad and others, 2016).

We hypothesise that most unconfined Antarctic ice shelves are unable to provide buttressing of greater than 0.05 because they are unable to sustain the large azimuthal stresses required without the formation of fractures that weaken the ice. For substantial hoop-stress buttressing the azimuthal strain rate needs to be significantly larger than the radial strain rate. For typical radial strain rates of $0.01 \mathrm{a}^{-1}$ with a rate factor $A_{-10}$ this leads to stresses on the order of $75 \mathrm{kPa}$. Stresses larger than this are likely to generate fractures (Vaughan, 1993) and once fractures are initiated the ice can no longer support such large stresses (Borstad and others, 2016). In addition, laboratory-scale fluid-mechanical experiments have shown that radially-flowing shear-thinning fluids (Glen's flow law implies ice is shear thinning) produce radial fractures (Sayag and others, 2012).

Ice shelves with larger buttressing from hoop-stresses, such as Land and Mertz, form ice tongues that are potentially further stabilised by sea ice for much of the year. Figure 1 shows the unconfined regions of each ice shelf in April 2009 at the end of the austral summer (this year corresponds to when the majority of the velocity data were collected; Rignot and others, 2011, 2017). Equivalent plots for September 2009 are shown in SM; Figure S7. In both periods extensive regions of landfast sea ice are visible around Land and Mertz ice shelves. In our modelling, these shelves have lower rate factors $\left(A_{-10}\right)$ and small radii of curvature allowing more substantial buttressing from hoop stresses. As seen from the theoretical examples, buttressing increases for increased ice viscosity and decreased radius of curvature at the upstream boundary.

Despite the potential for hoop stresses to generate buttressing in unconfined ice shelves, our findings support those of Fürst and others (2016), who concluded that these regions should be classed as passive. However, buttressing of $10 \%$ or greater could be achieved for unconfined ice shelves that maintain a high effective viscosity, through preventing the formation of fractures and crevasses, possibly through extra stabilisation from sea ice for large parts of the year. Loss of extensive sea ice has previously been linked to accelerations in ice flow and reductions in ice-shelf extent (Miles and others, 2017; Greene and others, 2018; Massom and others, 2018). However, we can not discount that the sea ice is providing a substantial portion of the buttressing we are attributing to hoop stresses.

There are two main limitations of this application of the hoop-stress theory to Antarctic ice shelves. Firstly, the unconfined regions at the downstream end of ice shelves do not form perfect sectors of an annulus and flowlines are not azimuthally symmetric. In particular, there is an imprint of the upstream ice thickness and speed at the transition from laterally-confined to unconfined flow. The shear of the ice shelf between lateral pinning points while the shelf is confined means that ice flow is typically fastest and ice thicker in the centre of the shelf. As a result, the calving front usually extends further in the centre of the shelf than at the flanks, leading to the calving front having a smaller radius of curvature than the annulus we consider.

Here we have taken the simplest approach in order to produce first-order estimates of the magnitude of hoop-stress buttressing generated by unconfined sections of ice shelves. One way to avoid fitting an approximate annulus geometry would be to analyse strain rates along a $2 \mathrm{D}$ streamtube (bounded by two streamlines) to determine the hoop-stress buttressing from lateral spreading of that streamtube. One reason that this is not effective is that our theory ignores lateral variation in flow, which may 
result from lateral variations in ice thickness. There is also noise in the data, which results from the compilation of multiple sets of interferometric synthetic-aperture radar and optical featuretracking data over multiple time periods (Rignot and others, 2011, 2017). Therefore it is not possible to make direct comparisons with the theoretical model and the physical processes that determine the observed variations of the extensional strain rate; do they result from hoop stresses, shear or noise in the data?

A second limitation that applies both to the approximate annulus and streamtube method is that in order to determine hoop stress it is necessary to know both the strain rates and effective viscosity. Strain rates can be calculated from surface velocities. Here we have used a range of rate factors in the ice rheology and considered a simple comparison between data (ice thickness and speed) along flowlines and model output in the steady state, to determine which rate factor is most appropriate. This could be improved by assimilating the ice flow in an ice-shelf model and tuning the rheological parameters to match with observed velocities (MacAyeal, 1993; Gillet-Chaulet and others, 2012; Arthern and others, 2015; Fürst and others, 2015). The stress field could then be obtained directly from the model.

However, despite these limitations, our simplified approach has several advantages over using more complex geometries to partition ice shelves or taking a data-assimilation approach. Firstly, it effectively characterises the large-scale flow structure without incorporating the presence of significant observational noise, which is problematic when computing velocity gradients. Secondly, the annulus-based approach provides insight into the fundamental controls on hoop-stresses. For example, the clear relationship between radius of curvature and contributions to hoop-stress buttressing, apparent in our numerical results, can be directly linked to the relative magnitudes of radial and azimuthal extension through Eqn (16). Moreover, given that our aim is to assess if significant hoop-stress buttressing is generated in unconfined portions of Antarctic's ice shelves, rather than quantifying buttressing, these limitations do not affect our main conclusions.

\section{Conclusions}

Theoretically, unconfined ice shelves can provide buttressing via hoop stresses, the viscous resistance to azimuthal extension for a radially spreading flow (Morland and Zainuddin, 1987; Pegler and Worster, 2012, 2013). The magnitude of hoop-stress buttressing is dependent on the difference between the rate of azimuthal and radial spreading, the radius of curvature, the length of the unconfined ice shelf and the effective viscosity, which is dependent on the rheological rate factor and extent of ice damage. High positive hoop-stress buttressing can be produced by rapidly-diverging, thick ice shelves that have a high effective viscosity.

When we compare our results from idealised modelling with ice thickness and flow speed along flowlines, rate factors appropriate for relatively warm ice are required to best-match observations. This suggests that unconfined ice shelves consist of weak ice with a low effective viscosity, which most likely results from the presence of a large number of fractures and damaged ice. In order to contribute positively to hoop-stress buttressing, the azimuthal strain rate must be larger than the radial strain rate. For typical radial strain rates observed in Antarctic ice shelves, the required azimuthal strain rates produce extensional stresses that are at the lower bound of those that cause fracturing. Once the ice is damaged it is no longer able to sustain high extensional stresses.

We have shown that some Antarctic ice shelves can provide buttressing equal to approximately $10 \%$ of the extensional driving stress, with rate factors appropriate for ice at $-10^{\circ} \mathrm{C}$. These ice shelves are stabilised by the presence of sea ice, which may prevent large-scale fracturing and break-up. This suggests that the presence of sea ice is vital in order for an ice shelf to advance into open ocean, without fracturing and maintaining significant hoop-stress buttressing. Pinned sea ice may act like a preliminary ice shelf, reducing ice-fracturing. Processes of this nature may be important when considering the growth of ice sheets during glacial cycles.

Supplementary material. The supplementary material for this article can be found at https://doi.org/10.1017/jog.2019.101.

Acknowledgments. The authors would like to thank Robert Arthern for his helpful and insightful comments during the development of this work. We are also grateful for the comments from our two reviewers and the scientific editor, which helped to improve the manuscript. We acknowledge funding from NSF (award number 1743310).

\section{References}

Arthern RJ, Hindmarsh RCA and Williams CR (2015) Flow speed within the Antarctic ice sheet and its controls inferred from satellite observations. Journal of Geophysical Research: Earth Surface 120(7), 1171-1188. doi: 10.1002/2014JF003239

Borstad C and 5 others (2016) A constitutive framework for predicting weakening and reduced buttressing of ice shelves based on observations of the progressive deterioration of the remnant Larsen B ice shelf. Geophysical Research Letters 43(5), 2027-2035. doi: 10.1002/2015GL067365

Cuffey KM and Paterson WSB (2010) The Physics of Glaciers, 4th Edn. Academic Press.

Fretwell P and 59 others (2013) Bedmap2: improved ice bed, surface and thickness datasets for Antarctica. The Cryosphere 7(1), 375-393. doi: 10. 5194/tc-7-375-2013

Fürst JJ and 7 others (2015) Assimilation of Antarctic velocity observations provides evidence for uncharted pinning points. The Cryosphere 9(4), 1427-1443. doi: 10.5194/tc-9-1427-2015

Fürst JJ and 6 others (2016) The safety band of Antarctic ice shelves. Nature Climate Change 6(5), 479-482. doi: 10.1038/nclimate2912

Gillet-Chaulet F and 8 others (2012) Greenland ice sheet contribution to sealevel rise from a new-generation ice-sheet model. The Cryosphere 6(6), 1561-1576. doi: 10.5194/tc-6-1561-2012

Goldberg DN, Snow K, Gourmelen N, Kimura S and Millan R (2018) How accurately should we model ice shelf melt rates? Geophysical Research Letters 46(1), 189-199. doi: 10.1029/2018g1080383

Greene CA, Young DA, Gwyther DE, Galton-Fenzi BK and Blankenship DD (2018) Seasonal dynamics of Totten ice shelf controlled by sea ice buttressing. The Cryosphere 12(9), 2869-2882. doi: 10.5194/tc-12-2869-2018

Gudmundsson GH (2013) Ice-shelf buttressing and the stability of marine ice sheets. The Cryosphere 7(2), 647-655. doi: 10.5194/tc-7-647-2013

Haseloff M and Sergienko OV (2018) The effect of buttressing on grounding line dynamics. Journal of Glaciology 64(245), 417-431. doi: 10.1017/jog.2018.30

Kowal KN, Pegler SS and Worster MG (2016) Dynamics of laterally confined marine ice sheets. Journal of Fluid Mechanics 790, R2. doi: 10.1017/jfm. 2016.37

MacAyeal DR (1989) Large-scale ice flow over a viscous basal sediment: theory and application to ice stream B, Antarctica. Journal of Geophysical Research: Solid Earth 94(B4), 4071-4087. doi: 10.1029/JB094iB04p04071

MacAyeal DR (1993) A tutorial on the use of control methods in icesheet modeling. Journal of Glaciology 39(131), 91-98. doi: 10.3189/ S0022143000015744

Massom RA and 5 others (2018) Antarctic ice shelf disintegration triggered by sea ice loss and ocean swell. Nature 558(7710), 383-389. doi: 10.1038/ s41586-018-0212-1

Miles BW, Stokes CR and Jamieson SS (2017) Simultaneous disintegration of outlet glaciers in Porpoise Bay (Wilkes Land), East Antarctica, driven by sea ice break-up. The Cryosphere 11(1), 427-442. doi: 10.5194/tc-11-427-2017

Morland LW (1987) Unconfined ice-shelf flow. In: Van der Veen CJ, and Oerlemans J (eds), Dynamics of the West Antarctic Ice Sheet, pp. 99-116. doi: 10.1007/978-94-009-3745-1_6

Morland LW and Zainuddin R (1987) Plane and radial ice-shelf flow with prescribed temperature profile. In Van Der Veen CJ and Oerlemans J (eds), Dynamics of the West Antarctic Ice Sheet. Dordrecht: Springer, pp. 117-140. doi: 10.1007/978-94-009-3745-1_7 
Pegler SS (2016) The dynamics of confined extensional flows. Journal of Fluid Mechanics 804, 24-57. doi: 10.1017/jfm.2016.516

Pegler SS, Kowal KN, Hasenclever LQ and Worster MG (2013) Lateral controls on grounding-line dynamics. Journal of Fluid Mechanics 722, R1. doi: 10.1017/jfm.2013.140

Pegler SS, Lister JR and Worster MG (2012) Release of a viscous power-law fluid over an inviscid ocean. Journal of Fluid Mechanics 700(April), 63-76. doi: $10.1017 / \mathrm{jfm} .2012 .91$

Pegler SS and Worster MG (2012) Dynamics of a viscous layer flowing radially over an inviscid ocean. Journal of Fluid Mechanics 696(March), 152-174. doi: 10.1017/jfm.2012.21

Pegler SS and Worster MG (2013) An experimental and theoretical study of the dynamics of grounding lines. Journal of Fluid Mechanics 728, 5-28. doi: 10.1017/jfm.2013.269

Rack W and Rott H (2004) Pattern of retreat and disintegration of the Larsen B ice shelf, Antarctic Peninsula. Annals of Glaciology 39SEP, 505-510. doi: 10.3189/172756404781814005

Reese R, Gudmundsson GH, Levermann A and Winkelmann R (2018) The far reach of ice-shelf thinning in Antarctica. Nature Climate Change 8(1), 53-57. doi: 10.1038/s41558-017-0020-x

Rignot E and 5 others (2004) Accelerated ice discharge from the Antarctic Peninsula following the collapse of Larsen B ice shelf. Geophysical Research Letters 31(18), L18401. doi: 10.1029/2004GL020697

Rignot E, Mouginot J and Scheuch B (2017) MEaSUREs InSAR-Based Antarctica Ice Velocity Map, Version 2. NASA National Snow and Ice Data Center Distributed Active Archive Center. doi: 10.5067/D7GK8F5J8M8R.

Rignot E, Mouginot J and Scheuchl B (2011) Ice flow of the Antarctic ice sheet. Science 333(6048), 1427-1430. doi: 10.1126/science.1208336

Robison RAV, Huppert HE and Worster MG (2010) Dynamics of viscous grounding lines. Journal of Fluid Mechanics 648, 363. doi: 10.1017/ S0022112009993119

Sayag R, Pegler SS and Worster MG (2012) Floating extensional flows. Physics of Fluids 24(9), 091111. doi: 10.1063/1.4747184

Scambos TA, Bohlander JA, Shuman CA and Skvarca P (2004) Glacier acceleration and thinning after ice shelf collapse in the Larsen B embayment, Antarctica. Geophysical Research Letters 31(18), 2001-2004. doi: 10.1029/ 2004GL020670

Schoof C (2007) Marine ice-sheet dynamics. Part 1. The case of rapid sliding. Journal of Fluid Mechanics 573, 27. doi: 10.1017/S0022112006003570

Vaughan DG (1993) Relating the occurrence of crevasses to surface strain rates. Journal of Glaciology 39(132), 255-266. doi: 10.3189/ S0022143000015926

Wearing MG (2016) The Flow Dynamics and Buttressing of Ice Shelves ( $\mathrm{PhD}$ thesis). University of Cambridge.

Wearing MG, Hindmarsh RC and Worster MG (2015) Assessment of ice flow dynamics in the zone close to the calving front of Antarctic ice shelves. Journal of Glaciology 61(230), 1194-1206. doi: 10.3189/ 2015JoG15J116

Young DM (1971) Iterative Solution of Large Linear Systems. Elsevier. ISBN 9780127730509. doi: 10.1016/C2013-0-11733-3.

\section{APPENDIX A. Axisymmetric, radially-spreading shelf: force balance}

The horizontal depth-integrated force-balance equation from the Shallow Shelf Approximation (Morland, 1987; MacAyeal, 1989; Pegler and others, 2012), takes the form

$$
\nabla \mu H(\nabla \cdot \mathbf{u})+\nabla \cdot(\mu H \mathbf{e})=\frac{\rho g^{\prime}}{2} H \nabla H
$$

For an axisymmetric radial flow, with no azimuthal variation in thickness or speed, spreading from an origin at $r=0$, the horizontal velocity takes the form $\mathbf{u}=(u(r), 0)$. In cylindrical polar coordinates the strain-rate tensor is

$$
\mathbf{e}=\frac{1}{2}\left(\nabla \mathbf{u}+(\nabla u)^{T}\right)=\left(\begin{array}{cc}
\frac{\partial u}{\partial r} & 0 \\
0 & \frac{u}{r}
\end{array}\right)
$$

and the divergence in the horizontal velocity is

$$
\nabla \cdot \mathbf{u}=\frac{1}{r} \frac{\partial(r u(r))}{\partial r}=\frac{\partial u}{\partial r}+\frac{u}{r}
$$

Therefore the radial component of the force balance Eqn (A1) becomes

$$
\begin{gathered}
\frac{\partial}{\partial r}\left(\mu H\left(\frac{\partial u}{\partial r}+\frac{u}{r}\right)\right)+\frac{\partial}{\partial r}\left(\mu H \frac{\partial u}{\partial r}\right)+\frac{\mu H}{r} \frac{\partial u}{\partial r}-\mu H u r^{2}=\frac{\rho g^{\prime}}{2} H \frac{\partial H}{\partial r} \\
\Rightarrow \frac{\partial}{\partial r}\left(\mu H\left(2 \frac{\partial u}{\partial r}+\frac{u}{r}\right)\right)+\mu H \frac{\partial}{\partial r}\left(\frac{u}{r}\right)=\frac{\rho g^{\prime}}{2} H \frac{\partial H}{\partial r}
\end{gathered}
$$

The first term on the LHS is the radial derivative of the vertically-integrated isotropic stress and along-flow (in this case, radial) deviatoric stress (the equivalent to Cartesian cases). The second term on the LHS is the depth-integrated radial gradient in the azimuthal strain rate, multiplied by the effective viscosity. Here the radial force-balance equation is split into two terms on the LHS: (1) the extensional terms resulting from the radial derivative of the vertically-integrated isotropic stress and the radial derivative of the radial deviatoric stress; and (2) the hoop-stress term resulting from the radial derivative of the azimuthal strain rates. These additional terms (in comparison with the Cartesian case) are included when working in cylindrical polar coordinates because the ice shelf must spread laterally in additional to radially when flowing in a divergent geometry to ensure incompressibility, Figure 9. The along-flow terms are the equivalent to those in the Cartesian case, however here an additional azimuthal component results from the divergent flow.

These equations demonstrating how hoop stresses arise in radially spreading flows have been derived previously by Morland and Zainuddin (1987), Pegler and Worster $(2012,2013)$ 
a

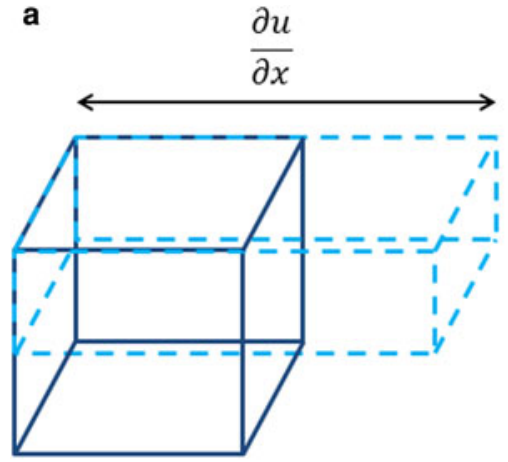

$\frac{\partial w}{\partial z}=-\frac{\partial u}{\partial x} \quad \frac{\partial w}{\partial z}=-\frac{\partial u}{\partial r}-\frac{u}{r}$

b

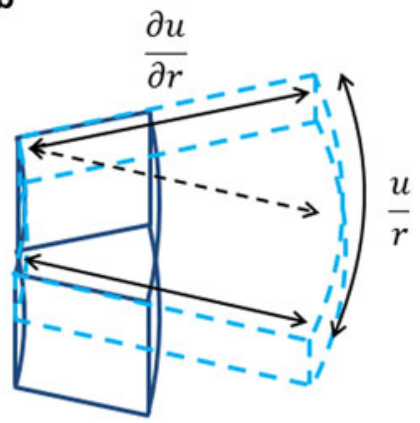

Fig. 9. Schematic of incompressibility terms in a laterally confined (a) and radially spreading (b) flow.

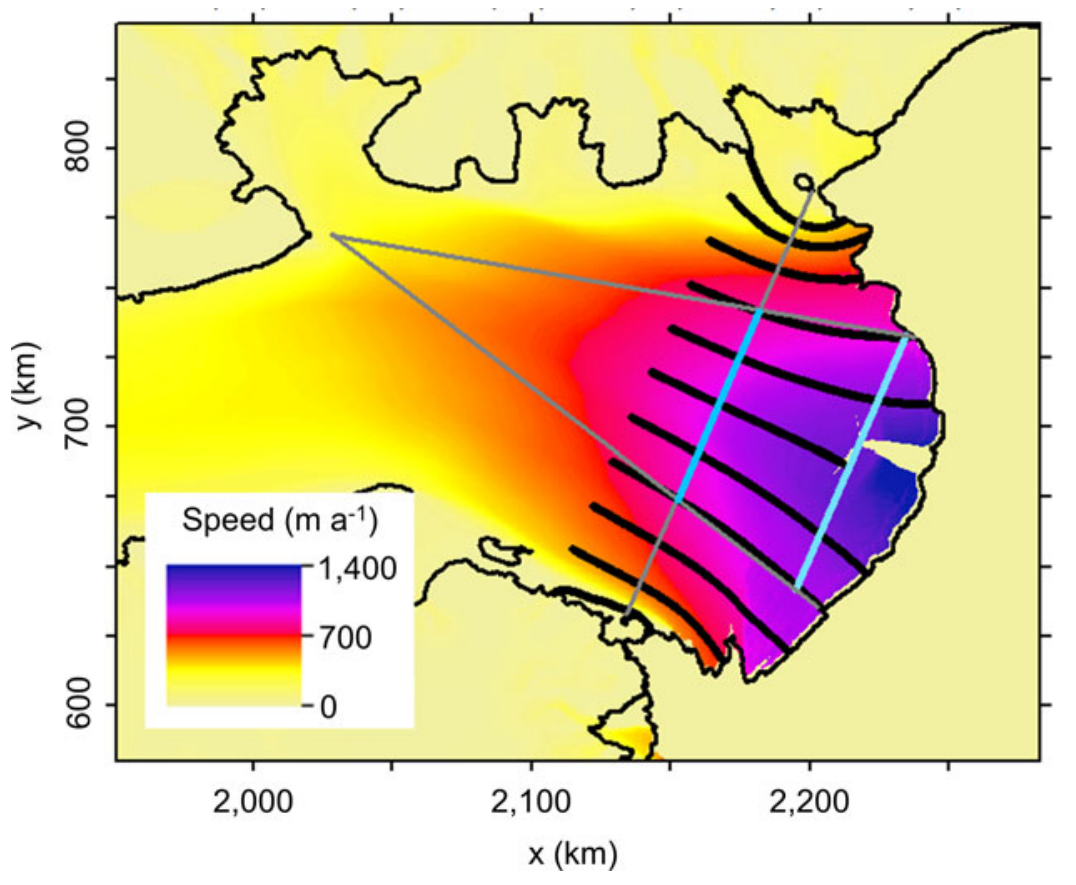

Fig. 10. Map showing the original 10 flowlines spanning the width of Amery Ice Shelf used to determine the extent of the laterally spreading region.

\section{APPENDIX B. Approximation to Antarctic ice shelves: method}

We calculate flowlines and perform numerical calculations in MATLAB and determine the geometry of the annulus in ArcMap. We calculate flowlines from 10 equally-spaced points spanning the width of the ice shelf just upstream of the transition from laterally confined to unconfined, as seen in Figure 10. These flowlines are used to determine the approximate lateral extent of the ice that spreads in a manner similar to a sector of an annulus, as discussed in the main text. We draw a line perpendicular to the central flowline between the final lateral pinning points signifying the upstream boundary of the annulus. We consider the intersection of this line with the outermost flowlines of the spreading and unconfined shelf to mark the upstream lateral boundaries of the annulus. Once the geometry of the upstream boundary is established, a second set of six flowlines originating from equally spaced points along the upstream boundary are calculated, Figure 7a. The downstream boundary is marked by a second line parallel to the first, which spans the downstream limit of the flowlines before reaching the calving front. The two parallel lines and lateral flowlines form an approximate trapezium, or sector of an annulus.

Two straight lines are drawn between the edges of the upstream and downstream boundaries, which are extended upstream until they intersect. Using the distance measuring tool in ArcMap, the distance from the upstream boundary to the intersection is determined giving the approximate radius of curvature at the upstream boundary. The distance from the upstream to downstream boundary is measured, as well as the length of the upstream and downstream boundaries, giving the width of the flow at these locations.

Ice thickness and speed are sampled along the flowlines. The flux across the upstream and downstream boundaries is calculated by averaging the ice thickness and speed at the intersection of each flowline with the boundary and then multiplying by the width of the flow. Assuming the shelf is in steady state, the difference between the flux over the upstream and downstream boundaries gives the volume of ice lost (or gained) through basal melting (or freeze-on and surface accumulation). The average melt (freeze-on) rate is calculated by dividing the flux difference by the area of the annulus. 